\title{
Phase Shifting the Retinal Circadian Clock: xPer2 mRNA Induction by Light and Dopamine
}

\author{
Brooke M. Steenhard ${ }^{1,2}$ and Joseph C. Besharse ${ }^{1}$ \\ 1Department of Cell Biology, Neurobiology, and Anatomy, Medical College of Wisconsin, Milwaukee, Wisconsin 53226, and \\ 2Department of Anatomy and Cell Biology, The University of Kansas Medical Center, Kansas City, Kansas
}

\begin{abstract}
A circadian clock is located in the retinal photoreceptors of the African clawed frog Xenopus laevis. These photoreceptor clocks are thought to govern a wide variety of output rhythms, including melatonin release and gene expression. Both light and dopamine phase shift the retinal clock in a phase-dependent manner. Two homologs of the Drosophila period gene have been cloned in Xenopus, and one of these (xPer2) is acutely regulated by light. Light and dopamine induce $x P e r 2$ mRNA in a similar manner. In addition, the increase of $x$ Per2 $\mathrm{mRNA}$ in response to light and
\end{abstract}

dopamine is the same at all times of day tested. In contrast, $x$ Per1 mRNA exhibits circadian oscillations but is relatively insensitive to phase-shifting treatments of light or dopamine. Our data suggest that $x$ Per2 functions as the molecular link between the light/dark cycle and the circadian clock.

Key words: circadian rhythms; circadian clock; period genes; phase shifting; light induction; retina; photoreceptors; dopamine; D2 receptors; Xenopus
Information about time of day is provided to organisms by external stimuli such as light and by circadian clocks. Circadian clocks consist of a set of genes that govern rhythmic events in the absence of external timing cues such as light (Green, 1998). Clocks are modulated by environmental light via daily resetting in response to the imposed light/dark cycle. Resetting (or phase shifting) of the clock is initiated when light causes acute changes in the activity or abundance of central clock gene products (Pittendrigh, 1993).

Circadian rhythms are generated by activating the transcription of a set of genes that ultimately enter the nucleus and inhibit their own transcription. This negative feedback mechanism is conserved in all species (Dunlap, 1999). In Drosophila, the period ( per) gene is a clock gene that negatively regulates its own transcription. PER only enters the nucleus with a protein partner called TIMELESS (TIM). Light applied at night results in the rapid degradation of TIM protein (Hunter-Ensor et al., 1996; Lee et al., 1996; Myers et al., 1996; Zeng et al., 1996). Thus, light changes the abundance of both per and tim mRNA, by acutely affecting TIM and by interrupting the normal negative feedback of per. The degradation of TIM by light resets the clock to an earlier or later time, depending on the time of day light is delivered.

A different mechanism exists for phase shifting the mammalian suprachiasmatic nucleus (SCN) involving period gene products. There are three period gene homologs in mice (mPer1, mPer2, and $m$ Per3) that are rhythmically expressed (Zylka et al., 1998) and are able to function as transcriptional inhibitors (Jin et al., 1999; Kume et al., 1999). Light causes an increase in the abundance of the mRNA of two of these genes, mPerl and mPer2 (Albrecht et al., 1997; Shearman et al., 1997; Shigeyoshi et al., 1997; Takumi et al., 1998; Zylka et al., 1998; Field et al., 2000). Treatment of mice with antisense mPer1 oligonucleotides blocks phase shifts induced by light, providing direct evidence that changes in mPerl mRNA contribute to the phase-shifting mechanism (Akiyama et al., 1999).

Phase shifting of the retinal circadian clock has been studied

Received July 17, 2000; revised Sept. 7, 2000; accepted Sept. 11, 2000.

This work was supported by National Institutes of Health Grant EY 02414 to J.C.B. We would like to thank Pam Megaw, Sheila Baker, Minhong Zhuang, Carla Green, and Greg Cahill for many valuable discussions concerning this work. A special thanks goes to Pam Megaw for doing the melatonin measurements. We also thank Cheryl Stucky and Maureen Neitz for critical reading of this manuscript.

Correspondence should be addressed to Dr. Joseph C. Besharse, Department of Cell Biology, Neurobiology, and Anatomy, Medical College of Wisconsin, 8701 Watertown Plank Road, Milwaukee, WI 53226. E-mail: jbeshars@mcw.edu. Copyright (C) 2000 Society for Neuroscience $0270-6474 / 00 / 208572-06 \$ 15.00 / 0$ primarily in Xenopus by measuring how light affects the rhythm of melatonin release by cultured eyecups (Besharse and Iuvone, 1983; Cahill and Besharse, 1991). Both light and dopamine are able to phase shift the retinal melatonin rhythm (Cahill and Besharse, 1991). Our previous work demonstrated that $x$ Per2 mRNA was rhythmic in a light/dark cycle (LD) but was maintained at constitutively low levels in constant darkness (DD), indicating that light plays a major role in the regulation of $x$ Per2 (Zhuang et al., 2000). In this report using the eyecup system, we show that light exposure increases $x$ Per 2 mRNA at all times of day tested. In a similar manner, $x$ Per 2 mRNA is increased by dopamine. Our data suggest that in Xenopus retina, changes in $x P e r 2$ mRNA play a critical role in phase shifting.

\section{MATERIALS AND METHODS}

Animals. Mature male Xenopus laevis purchased from Nasco (Ft. Atkinson, WI) were maintained at $21^{\circ} \mathrm{C}$ on a $12 / 12 \mathrm{hr}$ light/dark cyclic lighting schedule (LD) for at least 2 weeks before all experiments. Zeitgeber time (ZT) is used by convention to denote the time of day relative to the normal lighting condition. ZT 0 is when lights are turned on, and ZT 12 is when lights are turned off. Animal care and experimental protocols involving these animals were performed in full compliance with the institutional and federal guidelines.

In vivo collections. Retinas were collected from Xenopus maintained in $\mathrm{LD}$ beginning at ZT 0 and proceeding for $6 \mathrm{hr}$ after lights were turned on (normal room lights). For the ZT 0 group, animals were killed, and retinas were dissected using infrared illumination (FJW Optical, St. Palatine, IL). Normal lighting conditions were used for all other collections. Retinas were immediately frozen on dry ice and stored at $-80^{\circ} \mathrm{C}$.

Eyecup culture. A defined medium gassed with $95 \% \mathrm{O}_{2} / 5 \% \mathrm{CO}_{2}$ was used for dissection and culturing of the eyecups as described previously (Cahill and Besharse, 1991). In several experiments (see Figs. 4, 5c-f, $6 c-f$, 7), the defined medium was supplemented with $20 \%$ Wolf and Quimby's amphibian tissue culture medium (Life Technologies, Gaithersburg, MD). In all experiments (for exception, see Fig. 3b), $100 \mu \mathrm{M}$ 5-hydroxy-Ltryptophan was added to increase overall melatonin to measurable levels (Cahill and Besharse, 1990). Melatonin assays of culture medium (Cahill and Besharse, 1991) from each experiment showed that light and dopamine agonists inhibited melatonin release as expected (data not shown). This concentration of 5-hydroxy-L-tryptophan does not alter the phasing of the circadian oscillator when applied in a cyclic manner (Cahill et al., 1991).

Dissections were done 1-2 hr before normal dark onset. Eyecups were prepared by removing the anterior portion of the eye (cornea, lens, and vitreous) by a circular cut following the boundary of the iris. In most experiments, paired experimental and control eyecups from an individual animal were compared to reduce variability. For light induction experiments, single eyecups were set into baskets mounted in $35 \mathrm{~mm}$ culture dishes to orient the eyecup toward the light source (Pierce and Besharse, 1988). In experiments involving only drug pulses, five eyecups were cultured per $60 \mathrm{~mm}$ culture dish. Eyecups were maintained in darkness in a rotating incubator $(60 \mathrm{rpm})$. Fresh medium was exchanged at 6 or $12 \mathrm{hr}$ 
intervals. Light and dopamine treatments were delivered the following day beginning at three different times (ZT 2, ZT 10, and ZT 18). These times were chosen because we have studied previously phase resetting by light and dopamine at these times (Cahill and Besharse, 1991). All manipulations during the experiment were conducted under infrared illumination.

Light. A tungsten-halogen lamp (Oriel Corporation, Stanford, CT) at constant voltage $(12 \mathrm{~V})$ delivered light via mirrors to the eyecups in the rotating incubator at an intensity of $3-5 \times 10^{-4} \mathrm{~W} / \mathrm{cm}^{2}$ (measured using a radiometer from International Light, Newburyport, MA).

Drugs. Dopamine, quinpirole, and eticlopride were purchased from Research Biochemicals (Natick, MA). SKF 38393 was donated by Smith Kline and French Laboratories (SmithKline Beecham, Philadelphia, PA). Drug stocks $(100 \times)$ were prepared immediately before each experiment. Dopamine was solubilized in $100 \mathrm{mg} / \mathrm{ml}$ ascorbic acid. Quinpirole, eticlopride, and SKF 38393 were solubilized in water. Final drug concentrations were obtained by diluting stocks into culture medium that was exchanged to begin the drug pulse. Vehicle-alone groups received the same final concentration of ascorbic acid. The antagonist eticlopride was delivered for $15 \mathrm{~min}$ before adding additional drugs or light.

Retina collections. Retinas were harvested from the eyecup at indicated times after light or drug treatment using a dissecting microscope and either overhead room lights (light groups) or infrared lights (dark groups). Retinas were immediately frozen on dry ice and were stored at $-80^{\circ} \mathrm{C}$.

$R N A$ isolation and Northern blot analysis. Total RNA was isolated from individual retinas using Trizol (Life Technologies). RNA was separated on an agarose-formaldehyde gel and was transferred to a Bright Star positively charged nylon membrane (Ambion, Austin, TX). Hybridizations were done using Ultrahyb solution (Ambion) according to the manufacturer's instructions. Blots were hybridized overnight at $42^{\circ} \mathrm{C}$ with ${ }^{32} \mathrm{P}$-labeled probes $\left(1 \times 10^{6} \mathrm{cpm} / \mathrm{ml}\right)$. Final washes were at $42^{\circ} \mathrm{C}$ with $0.1 \times \mathrm{SSC}$ and $0.1 \%$ SDS

Probes. Single-strand DNA probes were generated by asymmetric PCR labeled with $\left.{ }^{32} \mathrm{P}\right] \mathrm{dCTP}$ (New England Nuclear, Boston, MA) and were purified using DyeEx spin columns (Qiagen, Hilden, Germany). Blots were sequentially hybridized to xPer2 (either nucleotides 36-182 or 575-1066 of GenBank AF199499), xPer1 (GenBank AF250547), and either actin (nucleotides 171-680 of GenBank AF079161) or randomprimed glyceraldehyde-3-phosphate dehydrogenase (GAPDH; GenBank J02642) probes for normalization.

Quantitative analysis. Four or five retinas from individual animals were analyzed in each group, and mean per gene responses are reported \pm SEM. The signal of $x$ Per1 or $x$ Per 2 mRNA from an individual retina was quantified using the Storm PhosphorImaging system (Molecular Dynamics, Sunnyvale, CA) and was normalized to the signal of either actin or GAPDH internal controls. The means of all groups are normalized to the untreated control. ANOVA with Tukey-Kramer multiple comparisons or $t$ test were done using InStat software (version 2.03).

\section{RESULTS}

In DD, $x$ Per 2 mRNA levels in retina remain low and arrhythmic. However, in LD, $x$ Per 2 mRNA exhibits a robust rhythm with higher levels during the light phase (Zhuang et al., 2000). In those experiments, samples were collected at $4 \mathrm{hr}$ intervals. To determine the extent of light induction occurring between 0 and $4 \mathrm{hr}$, frogs were exposed to continuous light beginning at the normal dark-to-light transition (ZT 0). Retinas were collected at various times after the onset of light, and the abundance of $x P e r 2$ mRNA was quantified by Northern blotting (Fig. 1). At $3 \mathrm{hr}$ after light onset, significant differences were seen in the abundance of $x$ Per 2 mRNA. The level of $x$ Per 2 mRNA continued to increase between 3 and $6 \mathrm{hr}$ to a level approximately threefold higher than that at ZT 0 .

To verify that light increases $x$ Per 2 mRNA in a similar manner in cultured retinas, a time course was repeated using Xenopus eyecups (Besharse and Dunis, 1983; Cahill and Besharse, 1991). Eyecups were dissected on the afternoon before the experiment and were cultured in constant darkness until a continuous bright white light $\left(3-5 \times 10^{-4} \mathrm{~W} / \mathrm{cm}^{2}\right)$ was delivered for $3 \mathrm{hr}$ (Fig. $\left.2 a, b\right)$ or for $6 \mathrm{hr}$ (Fig. 2c). Retinas were collected at various times after the beginning of the light treatment. In agreement with the in vivo data, cultured retinas required $3 \mathrm{hr}$ of light exposure to achieve a significant increase in the abundance of $x$ Per 2 mRNA compared with dark controls. Both the 10 and $13 \mathrm{~kb} x$ Per 2 mRNAs were increased by light and were quantified together for all experiments (Fig. 2a). On the basis of these data, we chose to assay for changes in $x$ Per 2 mRNA after $3 \mathrm{hr}$ of light in subsequent experiments.

If $x$ Per 2 is solely under the control of light, then its response to light should remain the same regardless of what time of day the light is delivered. Retinas were collected after $3 \mathrm{hr}$ of light exposure that began at early subjective day (Fig. 3a), late subjective day (Fig.

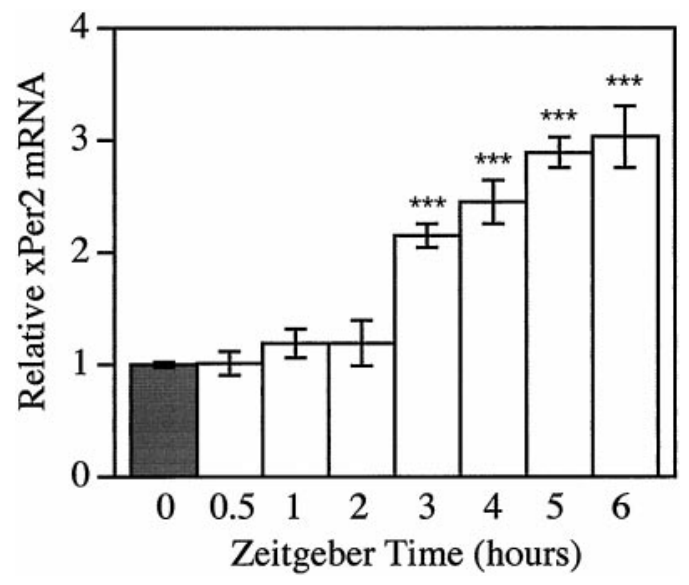

Figure 1. Three hours of light increase $x$ Per 2 mRNA in vivo. Total retinal RNA was prepared from Xenopus killed at various times after the onset of a 6 hr continuous light treatment delivered at ZT 0 . The abundance of $x$ Per2 mRNA was quantitated by Northern blotting, and the signal was normalized to an internal control (actin). The mean value was calculated from five retinas from individual animals and was normalized to the $0 \mathrm{hr}$ dark group (gray bar). Error bars indicate SEM. Significant differences were detected between the $3,4,5$, and $6 \mathrm{hr}$ light-treated groups (white bars) compared with the $0 \mathrm{hr}$ dark control group $(* * *<<0.001$, ANOVA). No significant differences were detected between the $0,0.5,1$, or 2 hr groups (ANOVA).

$3 b$ ), or subjective night (Fig. 3c). These times correspond to times for which phase-shifting data are available (Cahill and Besharse, 1991). At all three times of day, retinas receiving light have twofold to threefold more $x P e r 2$ mRNA than do dark controls.

The increase in $x$ Per 2 mRNA after a light pulse may serve to phase shift the retinal clock. In addition to light, dopamine phase shifts the retinal clock (Cahill and Besharse, 1991). To test whether dopamine would also increase $x$ Per 2 mRNA, quinpirole $(1 \mu \mathrm{M})$, a D2-like dopamine agonist, was delivered to eyecups for $3 \mathrm{hr}$. Retinas were collected at various times after the beginning of the treatment, and $x P e r 2$ mRNA levels were measured. The level of $x$ Per 2 mRNA was significantly increased after $3 \mathrm{hr}$ of quinpirole treatment (data not shown). Therefore, we chose to assay for changes in $x$ Per 2 mRNA levels after $3 \mathrm{hr}$ of drug treatments. Three hours of various concentrations of dopamine, quinpirole, or SKF 38393 (a D1-like agonist) were delivered to eyecups at ZT 10 (Fig. 4). Both dopamine and the D2-like agonist (quinpirole) in the nanomolar concentration range caused increases in $x$ Per 2 mRNA. The D1-like agonist SKF 38393 induced $x$ Per 2 mRNA, but only at high micromolar concentrations $(50 \mu \mathrm{M})$. These high concentrations of the D1 agonist likely cross-react with D2-like receptors (Munemura et al., 1980).

Dopamine $(500 \mathrm{~nm})$ increased $x$ Per $2 \mathrm{mRNA}$ at all three times of day (Fig. $5 a-c$ ). The increase in $x P e r 2$ mRNA was blocked by previous treatment with the D2-like antagonist eticlopride $(50 \mu \mathrm{M})$. Because light is known to stimulate retinal dopamine release (Boatright et al., 1989), the effect of light on $x$ Per 2 mRNA could be mediated via the release of dopamine. However, light-induced phase shifts are not blocked by previous treatment with eticlopride (Cahill and Besharse, 1991). In a similar manner, the light-induced increase in $x$ Per 2 mRNA was not blocked by treating eyecups with eticlopride before light exposure at ZT 10 (Fig. 5e). There may be a partial block by eticlopride in the light-induced increase of $x P e r 2$ mRNA at ZT 2 and ZT 18 (Fig. 5d,f). There was no significant difference, however, between the light and the light plus eticlopride groups at any time of day (ANOVA). Thus, it appears that light and dopamine increase $x$ Per 2 mRNA via parallel pathways as seen for phase shifting.

In contrast to $x$ Per2, $x$ Per1 mRNA is rhythmically expressed in LD and DD with peak levels at ZT 0 (Zhuang et al., 2000). To determine whether $x$ Per1 mRNA was sensitive to light or dopamine treatments, blots from the previous experiments were probed with $x$ Per1 cDNA. At ZT 2, both dopamine and light treatment induced 
$\mathbf{a}$
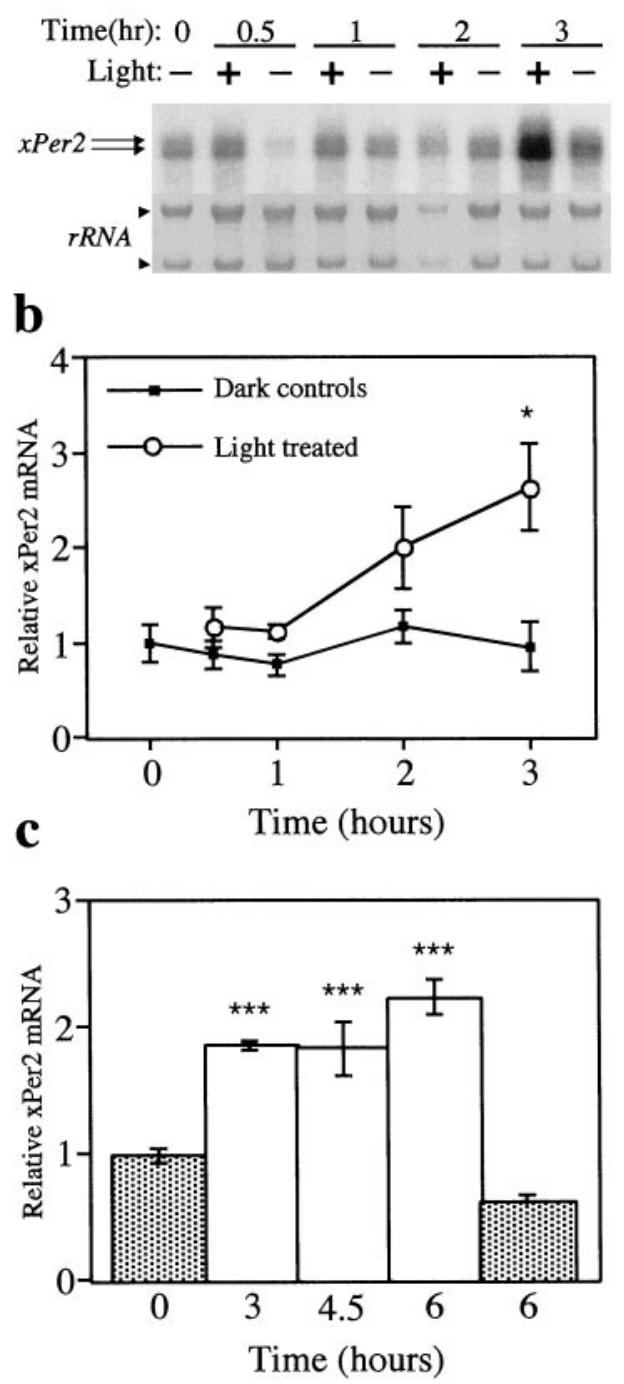

Figure 2. Three hours of light increase $x P e r 2$ mRNA in vitro. Eyecups were dissected the afternoon before the experiment and were cultured in constant darkness until a continuous light pulse $\left(3-5 \times 10^{-4} \mathrm{~W} / \mathrm{cm}^{2}\right)$ was delivered at either ZT $18(a, b)$ or ZT $2(c), a$, Top, xPer2 mRNA for all experiments was measured by Northern blotting. Each lane contains the total RNA from a single retina of an individual animal. Two $x P e r 2$ bands (arrows) at 10 and $13 \mathrm{~kb}$ were increased after $3 \mathrm{hr}$ of light. Both bands were quantitated in all experiments. Bottom, The abundance of the ribosomal RNA (arrowheads) was visualized by methylene blue staining of the blot. $b$, One eyecup from each animal received light (white circles), and the paired eyecup from the same animal was maintained in darkness (black squares). Retinas were collected at $0,0.5,1,2$, or $3 \mathrm{hr}$ after the beginning of the light pulse. The abundance of $x P e r 2$ mRNA was quantitated by Northern blotting, and the $x P e r 2$ signal was normalized to the signal of an internal control (GAPDH) for each individual retina. Mean values (4-5 retinas from individual animals) for each group were normalized to the $0 \mathrm{hr}$ dark control. The $3 \mathrm{hr}$ light-treated group was significantly different from the $3 \mathrm{hr}$ dark group $\left({ }^{*} p<0.05\right.$, ANOVA). No significant differences were detected between any of the dark control groups (ANOVA). $c$, Retinas were collected after $3,4.5$, or $6 \mathrm{hr}$ of light (white bars) or after 0 or $6 \mathrm{hr}$ of dark (gray bars). The abundance of $x$ Per 2 mRNA was quantitated by Northern blotting, and the $x$ Per 2 signal was normalized to the signal of an internal control (actin) for each individual retina. Mean values (4-5 retinas from individual animals) for each group were normalized to the $0 \mathrm{hr}$ dark control. The light groups were significantly different from both the 0 and $6 \mathrm{hr}$ dark controls $(* * * p<0.001$, ANOVA). No significant difference was detected between the 0 and $6 \mathrm{hr}$ dark groups (ANOVA).

$x$ Per1 mRNA to a modest but significant extent compared with the vehicle control group (Fig. $6 a, d$ ). Previous treatment with eticlopride blocked the effect of both light and dopamine at this time of day. However, there was no effect of light on $x$ Per1 mRNA levels at

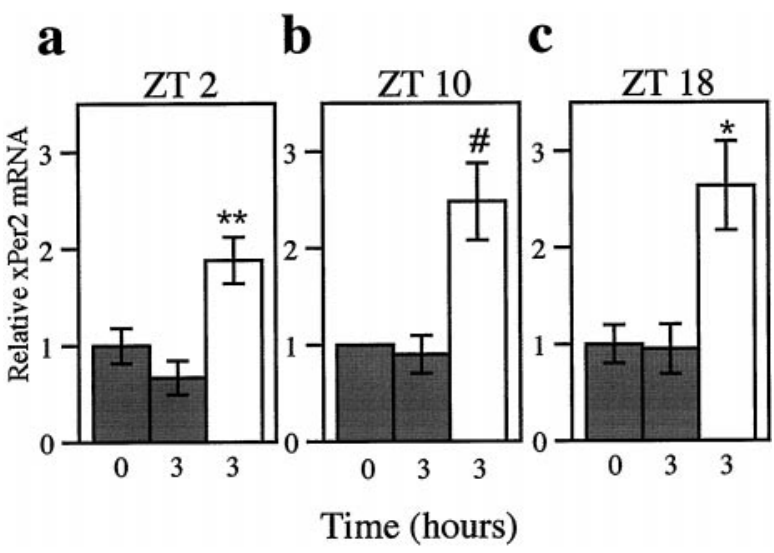

Figure 3. Light induces $x P e r 2 \mathrm{mRNA}$ at three different times of day. Three hour pulses of light $\left(3-5 \times 10^{-4} \mathrm{~W} / \mathrm{cm}^{2}\right)$ were delivered to eyecups beginning at early subjective day ( $a$; ZT 2$)$, late subjective day ( $b ; \mathrm{ZT} 10)$, or subjective night $(c ; \mathrm{ZT} 18)$. The abundance of $x$ Per 2 mRNA was quantitated as in Figure $2 b$, and values were normalized to the time 0 hr dark control. The mean value of each group was calculated from four retinas from individual animals, except in $b$ where $n=1$ for the $0 \mathrm{hr}$ time. Error bars indicate SEM. At all three times of day $(a-c)$, the light-treated groups (white bars) were significantly different from the dark controls ( $3 \mathrm{hr}$; gray bars) $\left({ }^{*} p<0.01,{ }^{*} p<0.05\right.$, ANOVA; \# $p<0.05, t$ test $)$.

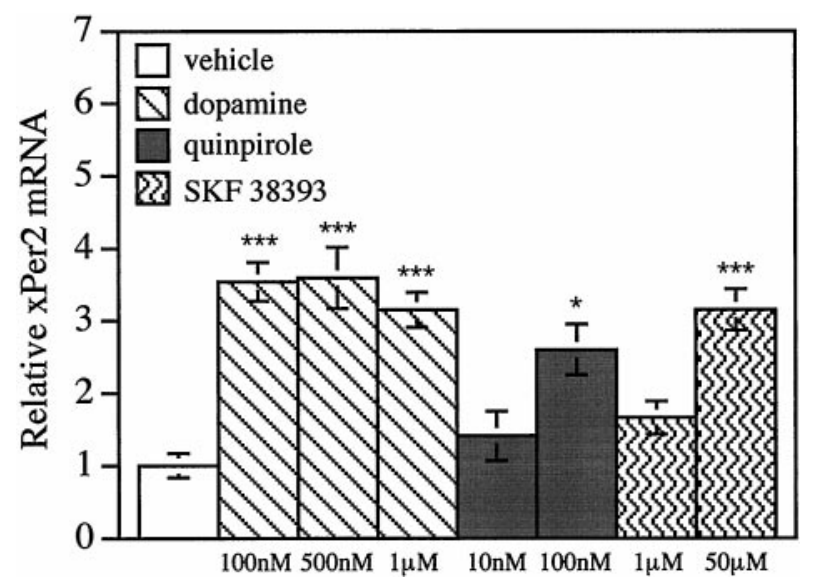

Figure 4. Dopamine increases $x P e r 2$ by activating D2-like dopamine receptors. Three hour treatments with various concentrations of vehicle (white bars), dopamine (bars with diagonal lines), the D2-like agonist quinpirole (gray bars), or the D1-like agonist SKF 38393 (bars with wavy lines) were delivered to eyecups at ZT 10. Eyecups were maintained in constant darkness throughout the experiment. The abundance of $x$ Per 2 mRNA was quantitated as in Figure $2 c$, and values were normalized to the vehicle-alone group. The mean value of each group was calculated from five retinas from individual animals. Error bars indicate SEM. Dopamine (100 nM, $500 \mathrm{nM}$, and $1 \mu \mathrm{M})$, quinpirole $(100 \mathrm{nM})$, and SKF $38393(50 \mu \mathrm{M})$ groups were significantly different from the vehicle-alone group $\left(* * * p<0.001,{ }^{*} p<\right.$ 0.05 , ANOVA).

ZT 10 or ZT 18 (Fig. 6e,f). A significant difference was detected between dopamine groups and the dopamine plus eticlopride groups at ZT 10 and ZT 18, but the induction was modest at best, and $x$ Per 1 mRNA values after dopamine treatment were not significantly different from vehicle controls (Fig. 6b,c). These data suggest that $x$ Perl mRNA is not induced by light or dopamine at times of day known to phase shift the retinal clock (Cahill and Besharse, 1991).

In the mouse SCN, mPerl mRNA is acutely increased by light and returns to control levels within $3 \mathrm{hr}$ (Zylka et al., 1998). To exclude the possibility that light induces $x$ Perl mRNA with faster kinetics as seen in mouse SCN, retinas were sampled at various times during $3 \mathrm{hr}$ of continuous light beginning at ZT 10 (Fig. 7). No significant differences were seen in $x$ Per 1 mRNA levels between the light and dark groups at any time during the treatment. After 3 
$\mathbf{a}$

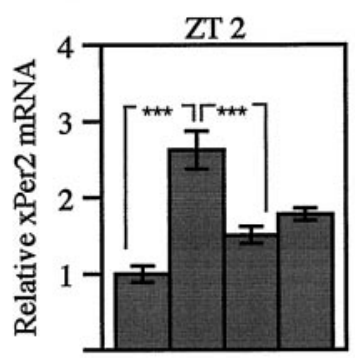

Dopamine: -++-

Eticlopride: $-\quad++$

Vehicle: +--

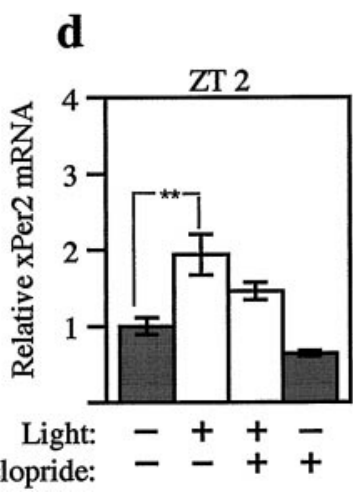

b

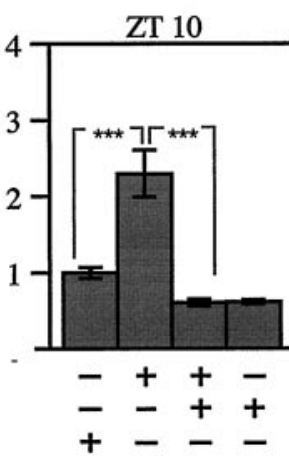

e

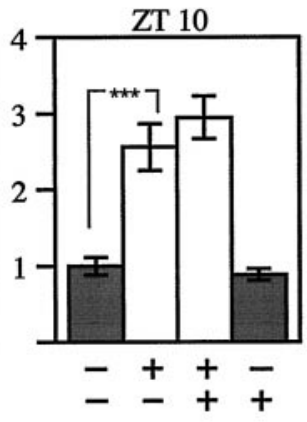

c

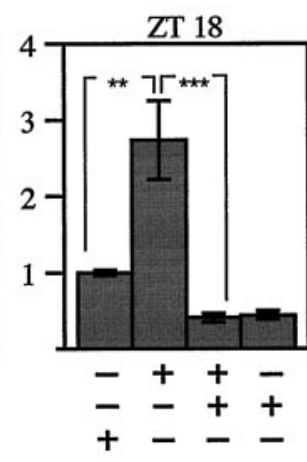

$\mathbf{f}$

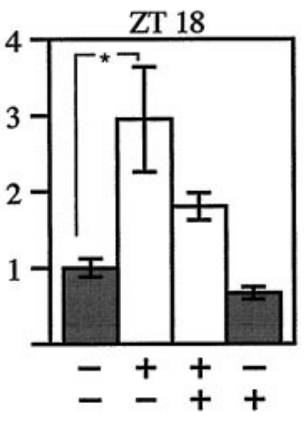

Figure 5. Light and dopamine act in parallel pathways to increase $x$ Per2 mRNA at three times of day. Three hours of dopamine $(a-c ; 500 \mathrm{nM})$ or light $\left(d-f ; 3-5 \times 10^{-4} \mathrm{~W} / \mathrm{cm}^{2}\right)$ were delivered to eyecups beginning at early subjective day $(a, d$; ZT 2 ), late subjective day ( $b, e ; \mathrm{ZT} 10)$, or subjective night ( $c, f ; \mathrm{ZT}$ 18) after previous treatment with $50 \mu \mathrm{M}$ eticlopride, a D2-like dopamine antagonist. The abundance of $x$ Per 2 mRNA was quantitated as in Figure $2 c$, and values were normalized to the vehicle-alone group for each experiment. The mean value of each group was calculated from four to five retinas from individual animals. Error bars indicate SEM. White bars indicate those groups receiving light; gray bars indicate those groups maintained in constant darkness. At all three times of day $(a-c)$, the dopamine-treated groups were significantly different from both the vehicle-alone groups and the dopamine plus eticlopride groups $\left({ }^{* *} p<0.001,{ }^{* *} p<0.01\right.$, ANOVA). At all three times of day $(d-f)$, the light-treated groups were significantly different from the vehicle-alone groups $(* * * p<$ $0.001,{ }^{*} p<<0.01,{ }^{*} p<0.05$, ANOVA). No significant differences were detected between the light and the light plus eticlopride groups at any time of day (ANOVA). $\mathbf{a}$

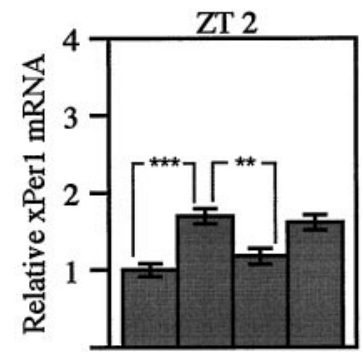

Dopamine: -++-

Eticlopride: $-\underline{+}+$

Vehicle: $+-\ldots$

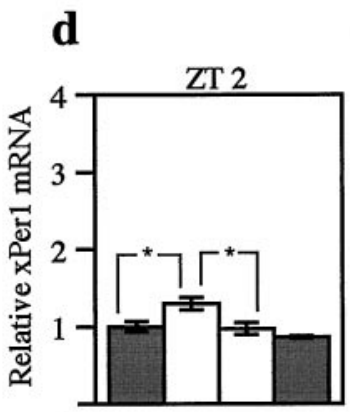

Light: -++- b
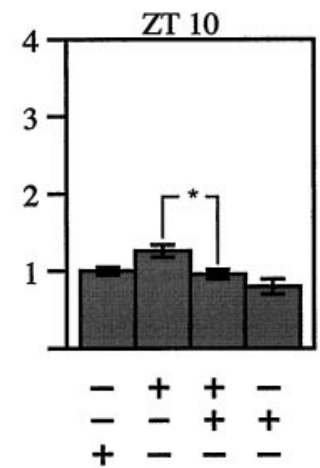

c
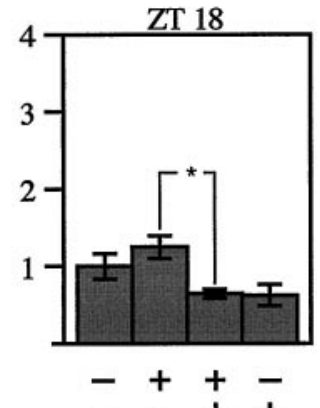

$-++$ e

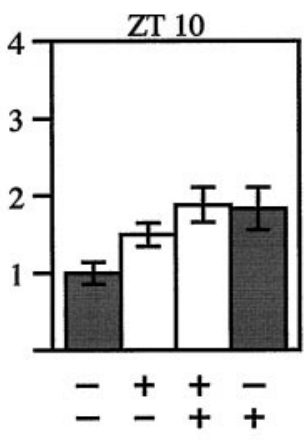

Figure 6. Three hour pulses of dopamine and light have modest effects on $x$ Per 1 . Northern blots from the experiments described in Figure 5 were hybridized with an xPer1 probe. Three hours of dopamine $(a-c ; 500 \mathrm{nM})$ or light $(d-f ; 3-5 \times$ $10^{-4} \mathrm{~W} / \mathrm{cm}^{2}$ ) were delivered to eyecups beginning at early subjective day ( $a, d$; ZT 2$)$, late subjective day $(b, e ; \mathrm{ZT} 10)$, or subjective night ( $c, f ; Z$ T 18$)$ after previous treatment with 50 $\mu \mathrm{M}$ eticlopride, a D2-like dopamine antagonist. The abundance of $x$ Perl mRNA was quantitated as in Figure $2 c$, and values were normalized to the vehicle-alone group for each experiment. The mean value of each group was calculated from four to five retinas from individual animals. Error bars indicate SEM. White bars indicate those groups receiving light; gray bars indicate those groups maintained in constant darkness. At ZT $2(a)$, the dopamine-treated group was significantly different from the vehicle-alone group $(* * * p<0.001$, ANOVA). At all three times of day $(a-c)$, the dopamine-treated groups were significantly different from the dopamine plus eticlopride groups $\left({ }^{*} p<0.01,{ }^{*} p<0.05\right.$, ANOVA). At ZT $2(d)$, the light-treated group was significantly different from both the control group and the light plus eticlopride group $(* p<0.05$ ANOVA). No significant differences were detected between the light-treated groups and either the control groups or the light plus eticlopride groups at ZT 10 or ZT 18 (e, f; ANOVA). hr of light, $x$ Per2 mRNA was increased compared with dark controls as expected (data not shown). Therefore, $x$ Perl mRNA is relatively insensitive to light and dopamine, whereas $x$ Per 2 mRNA is induced by both phase-shifting agents.

\section{DISCUSSION}

Our observations suggest that phase shifting in Xenopus retina involves the light- and dopamine-inducible $x$ Per 2 gene. Three hours 


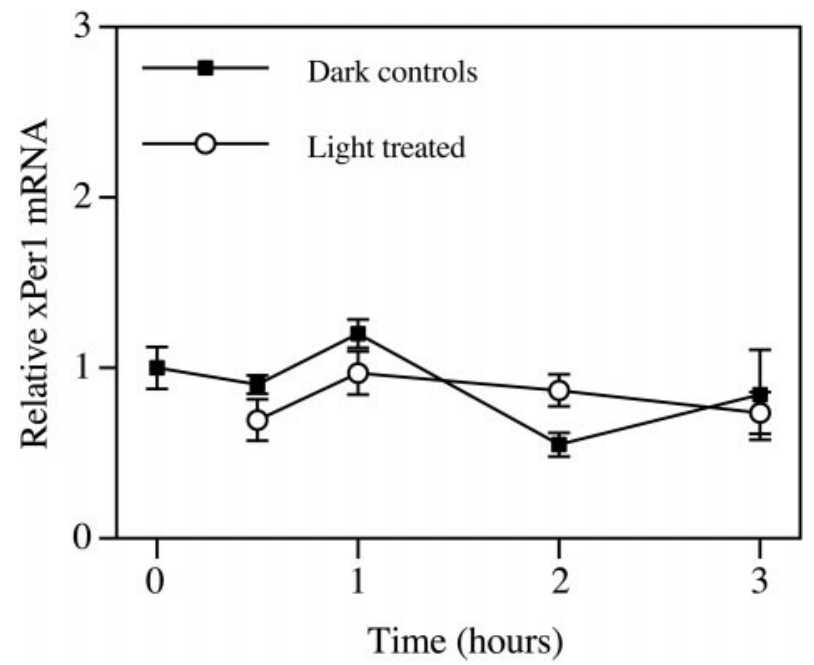

Figure 7. $x$ Per1 mRNA is not responsive to light at ZT 10 . Three hours of continuous light $\left(3-5 \times 10^{-4} \mathrm{~W} / \mathrm{cm}^{2}\right)$ were delivered to eyecups beginning at ZT 10. At indicated times after the beginning of the pulse, retinas were collected from either light-treated groups (white circles) or from dark controls (black squares). The abundance of $x$ Per1 mRNA was quantitated as in Figure $2 c$, and values were normalized to the $0 \mathrm{hr}$ dark group. The mean value of each group was calculated from four to five retinas from individua animals. Error bars indicate SEM. No significant differences were detected between any of the groups (ANOVA).

of light or dopamine increased the levels of $x$ Per 2 mRNA at all times of day, and the effect of dopamine was shown to be mediated by activation of D2-like dopamine receptors. Eticlopride, a D2 antagonist, blocked the effects of dopamine but not the effects of light, indicating that light increases $x P e r 2$ mRNA in a dopamineindependent manner. These features of acute stimulation of $x P e r 2$ mRNA are remarkably similar to the features of light- and dopamine-induced phase shifts of melatonin outflow shown in previous work on this system (Cahill and Besharse, 1991). Thus, increased XPER2 in daytime would be expected to reinforce the existing circadian phase, whereas increased xPER2 at night would lead to delay or advance phase shifts.

The mouse homolog of $x$ Per2 has been shown to be an indispensable part of the clock (Zheng et al., 1999). Both mPerl and mPer2 mRNA levels increase in SCN after a phase-shifting light treatment. In good agreement with the retinal $x P e r 2$ induction shown here, mPer2 in the SCN responds more slowly to light with maximal mRNA levels seen after 2-3 hr (Albrecht et al., 1997; Shearman et al., 1997; Takumi et al., 1998; Zylka et al., 1998). A recent study in quail retina shows that $q P e r 2 \mathrm{mRNA}$ is induced by light at both ZT 10 and ZT 16 with a similar time course to that of $x$ Per2 (Yoshimura et al., 2000). The per genes are thought to be negative elements in the transcription feedback loop. Positive elements in the feedback loop are CLOCK and BMAL1, which are basic helix-loop-helix transcription factors that activate transcription at $\mathrm{E}$ box elements within the promoters of the per genes (Gekakis et al., 1998; Hogenesch et al., 1998). In transient transfection assays, mPER2 inhibits CLOCK- and BMAL1-mediated transcription (Griffin et al., 1999; Jin et al., 1999; Kume et al., 1999). Recent evidence suggests that mPER2 also positively regulates bmal1 transcription (Shearman et al., 2000). Thus, changes in the level of Per 2 are expected to both increase and decrease the levels of other clock genes, which will change the phasing of the clock.

We could not detect light induction of $x$ Per1 mRNA in retina at times of day known to phase shift the retinal circadian clock. This is strikingly different from the light response shown for $m P e r 1$ in mouse SCN, in which mPer1 mRNA levels are maximally induced at 30-60 min and return to baseline levels by $3 \mathrm{hr}$ (Albrecht et al., 1997; Shearman et al., 1997; Shigeyoshi et al., 1997; Zylka et al., 1998). Injection of mPerl antisense oligonucleotides into SCN causes inhibition of light-induced phase shifts of behavior
(Akiyama et al., 1999). This suggests a major role for mPer1 in phase shifting within the mouse SCN. The disparity in the light induction of Perl between Xenopus retina and mouse SCN may reflect a fundamental difference in the mechanism of phase shifting between the retina and SCN. In the SCN, the light signal received in the retina is transmitted via the retinohypothalamic tract, causing neurotransmitter release onto $\mathrm{SCN}$ neurons. In the retina, a large proportion of clock cells are directly photosensitive (Cahill and Besharse, 1993).

The induction of $x$ Per 2 mRNA by dopamine in Xenopus retina is one of the first reports of a member of the per family being acutely responsive to a stimulus other than light (Balsalobre et al., 1998; Maywood et al., 1999). For many retinal processes, the effect of light is mimicked by dopamine. For example, light-evoked cone contraction is blocked by a D2-like dopamine antagonist (Pierce and Besharse, 1985), suggesting that dopamine release mediates light-evoked cone contraction (Besharse and Witkovsky, 1992). In contrast, light and dopamine act in parallel, convergent pathways to cause phase shifts in the melatonin rhythm (Cahill and Besharse, 1991). In those studies, a D2-like antagonist was able to block the effects of exogenous dopamine but was ineffective in blocking phase shifts induced by light. D2-like receptor activation causes a decrease in cAMP levels (Vallone et al., 2000). Increasing cAMP in Xenopus retina blocks phase shifting by dopamine but does not block phase shifting by light (Hasegawa and Cahill, 1999). Thus, light and dopamine cause phase shifts via different second messenger systems. We show that light and dopamine act in parallel to increase $x$ Per 2 mRNA. This may be the first point at which the light and dopamine pathways converge on the retinal clock.

Whether the induction of $x$ Per 2 mRNA is the initial event leading to phase shifting in Xenopus retina is an important question. Light may cause increases in $x$ Per 2 mRNA by stabilizing existing $x$ Per 2 mRNA or by activating new transcription of $x$ Per2. Both possibilities may require the synthesis or recruitment of an additional protein. Evidence from transgenic mice in which green fluorescent protein (GFP) is driven by the mPer1 promoter shows that acute light exposure increases GFP signal above controls, indicating a transcriptional mechanism for mPerl induction (Kuhlman et al., 2000). Three hours of light are required to increase $x$ Per 2 mRNA in Xenopus retina, similar to the induction of $m P e r 2$ in SCN (Albrecht et al., 1997; Shearman et al., 1997; Takumi et al., 1998; Zylka et al., 1998). In the SCN, however, there are other genes that respond to phase-shifting pulses of light with faster kinetics such as mPer1 (Shigeyoshi et al., 1997) and the immediateearly gene c-fos (Ikonomov and Stoynev, 1994; Shearman and Weaver, 1999). We do not believe that $x$ Per1 is involved in phase shifting in Xenopus retina because $x$ Per 1 mRNA is insensitive to phase-shifting pulses of light and dopamine. Fos induction by light is seen in amacrine and ganglion cells of the mammalian retina (Sagar and Sharp, 1990; Chambille et al., 1993; Koistinaho and Sagar, 1995; Huerta et al., 1997). It is possible that fos or other immediate-early genes induced by light could play a role in phase shifting the retinal clock.

A unique circadian organization exists in Xenopus retina. We found that $x$ Per1 mRNA levels are regulated by an endogenous clock and that $x P e r 2$ mRNA levels are regulated by light and dopamine. It appears that $x$ Per 2 provides the molecular link between light and the circadian clock in retina. Further analysis will provide an understanding of how $x$ Per 2 regulates the cycling of other clock components and alters rhythmic physiology downstream of the clock.

\section{REFERENCES}

Akiyama M, Kouzu Y, Takahashi S, Wakamatsu H, Moriya T, Maetani M, Watanabe S, Tei H, Sakaki Y, Shibata S (1999) Inhibition of light- or glutamate-induced mPer1 expression represses the phase shifts into the mouse circadian locomotor and suprachiasmatic firing rhythms. J Neurosci 19:1115-1121.

Albrecht U, Sun ZS, Eichele G, Lee CC (1997) A differential response of two putative mammalian circadian regulators, mper1 and mper2, to light. Cell 91:1055-1064.

Balsalobre A, Damiola F, Schibler U (1998) A serum shock induces cir- 
cadian gene expression in mammalian tissue culture cells. Cell 93:929-937.

Besharse JC, Dunis DA (1983) Rod photoreceptor disc shedding in eye cups: relationship to bicarbonate and amino acids. Exp Eye Res 36:567-579.

Besharse JC, Iuvone PM (1983) Circadian clock in Xenopus eye controlling retinal serotonin $N$-acetyltransferase. Nature 305:133-135.

Besharse JC, Witkovsky P (1992) Light-evoked contraction of red absorbing cones in the Xenopus retina is maximally sensitive to green light. Vis Neurosci 8:243-249.

Boatright JH, Hoel MJ, Iuvone PM (1989) Stimulation of endogenous dopamine release and metabolism in amphibian retina by light- and $\mathrm{K}+$-evoked depolarization. Brain Res 482:164-168.

Cahill GM, Besharse JC (1990) Circadian regulation of melatonin in the retina of Xenopus laevis: limitation by serotonin availability. J Neurochem 54:716-719.

Cahill GM, Besharse JC (1991) Resetting the circadian clock in cultured Xenopus eyecups: regulation of retinal melatonin rhythms by light and D2 dopamine receptors. J Neurosci 11:2959-2971.

Cahill GM, Besharse JC (1993) Circadian clock functions localized in Xenopus retinal photoreceptors. Neuron 10:573-577.

Cahill GM, Grace MS, Besharse JC (1991) Rhythmic regulation of retinal melatonin: metabolic pathways, neurochemical mechanisms, and the ocular circadian clock. Cell Mol Neurobiol 11:529-559.

Chambille I, Doyle S, Serviere J (1993) Photic induction and circadian expression of Fos-like protein. Immunohistochemical study in the retina and suprachiasmatic nuclei of hamster. Brain Res 612:138-150.

Dunlap JC (1999) Molecular bases for circadian clocks. Cell 96:271-290.

Field MD, Maywood ES, O'Brien JA, Weaver DR, Reppert SM, Hastings MH (2000) Analysis of clock proteins in mouse SCN demonstrates phylogenetic divergence of the circadian clockwork and resetting mechanisms. Neuron 25:437-447.

Gekakis N, Staknis D, Nguyen HB, Davis FC, Wilsbacher LD, King DP, Takahashi JS, Weitz CJ (1998) Role of the CLOCK protein in the mammalian circadian mechanism. Science 280:1564-1569.

Green CB (1998) How cells tell time. Trends Cell Biol 8:224-230.

Griffin Jr EA, Staknis D, Weitz CJ (1999) Light-independent role of CRY1 and CRY2 in the mammalian circadian clock. Science 286:768-771.

Hasegawa M, Cahill GM (1999) A role for cyclic AMP in entrainment of the circadian oscillator in Xenopus retinal photoreceptors by dopamine but not by light. J Neurochem 72:1812-1820.

Hogenesch JB, Gu YZ, Jain S, Bradfield CA (1998) The basic-helix-loophelix-PAS orphan MOP3 forms transcriptionally active complexes with circadian and hypoxia factors. Proc Natl Acad Sci USA 95:5474-5479.

Huerta JJ, Llamosas MM, Cernuda-Cernuda R, Garcia-Fernandez JM (1997) Fos expression in the retina of $\mathrm{rd} / \mathrm{rd}$ mice during the light/dark cycle. Neurosci Lett 232:143-146.

Hunter-Ensor M, Ousley A, Sehgal A (1996) Regulation of the Drosophila protein timeless suggests a mechanism for resetting the circadian clock by light. Cell 84:677-685.

Ikonomov OC, Stoynev AG (1994) Gene expression in suprachiasmatic nucleus and circadian rhythms. Neurosci Biobehav Rev 18:305-312.

Jin X, Shearman LP, Weaver DR, Zylka MJ, de Vries GJ, Reppert SM (1999) A molecular mechanism regulating rhythmic output from the suprachiasmatic circadian clock. Cell 96:57-68.

Koistinaho J, Sagar SM (1995) Light-induced c-fos expression in amacrine cells in the rabbit retina. Brain Res Mol Brain Res 29:53-63.

Kuhlman SJ, Quintero JE, McMahon DG (2000) GFP fluorescence reports Period1 circadian gene regulation in the mammalian biological clock. NeuroReport 11:1479-1482.
Kume K, Zylka MJ, Sriram S, Shearman LP, Weaver DR, Jin X, Maywood ES, Hastings MH, Reppert SM (1999) mCRY1 and mCRY2 are essential components of the negative limb of the circadian clock feedback loop. Cell 98:193-205.

Lee C, Parikh V, Itsukaichi T, Bae K, Edery I (1996) Resetting the Drosophila clock by photic regulation of PER and a PER-TIM complex. Science 271:1740-1744.

Maywood ES, Mrosovsky N, Field MD, Hastings MH (1999) Rapid downregulation of mammalian period genes during behavioral resetting of the circadian clock. Proc Natl Acad Sci USA 96:15211-15216.

Munemura M, Cote TE, Tsuruta K, Eskay RL, Kebabian JW (1980) The dopamine receptor in the intermediate lobe of the rat pituitary gland: pharmacological characterization. Endocrinology 107:1676-1683.

Myers MP, Wager-Smith K, Rothenfluh-Hilfiker A, Young MW (1996) Light-induced degradation of TIMELESS and entrainment of the Drosophila circadian clock. Science 271:1736-1740.

Pierce ME, Besharse JC (1985) Circadian regulation of retinomotor movements. I. Interaction of melatonin and dopamine in the control of cone length. J Gen Physiol 86:671-689.

Pierce ME, Besharse JC (1988) Circadian regulation of retinomotor movements. II. The role of GABA in the regulation of cone position. J Comp Neurol 270:279-287.

Pittendrigh CS (1993) Temporal organization: reflections of a Darwinian clock-watcher. Annu Rev Physiol 55:16-54.

Sagar SM, Sharp FR (1990) Light induces a Fos-like nuclear antigen in retinal neurons. Brain Res Mol Brain Res 7:17-21.

Shearman LP, Weaver DR (1999) Photic induction of Period gene expression is reduced in Clock mutant mice. NeuroReport 10:613-618.

Shearman LP, Zylka MJ, Weaver DR, Kolakowski Jr LF, Reppert SM (1997) Two period homologs: circadian expression and photic regulation in the suprachiasmatic nuclei. Neuron 19:1261-1269.

Shearman LP, Sriram S, Weaver DR, Maywood ES, Chaves I, Zheng B, Kume K, Lee CC, van der Horst GT, Hastings MH, Reppert SM (2000) Interacting molecular loops in the mammalian circadian clock. Science 288:1013-1019.

Shigeyoshi Y, Taguchi K, Yamamoto S, Takekida S, Yan L, Tei H, Moriya T, Shibata S, Loros JJ, Dunlap JC, Okamura H (1997) Light-induced resetting of a mammalian circadian clock is associated with rapid induction of the mPer1 transcript. Cell 91:1043-1053.

Takumi T, Matsubara C, Shigeyoshi Y, Taguchi K, Yagita K, Maebayashi Y, Sakakida Y, Okumura K, Takashima N, Okamura H (1998) A new mammalian period gene predominantly expressed in the suprachiasmatic nucleus. Genes Cells 3:167-176.

Vallone D, Picetti R, Borrelli E (2000) Structure and function of dopamine receptors. Neurosci Biobehav Rev 24:125-132.

Yoshimura T, Suzuki Y, Makino E, Suzuki T, Kuroiwa A, Matsuda Y, Namikawa T, Ebihara S (2000) Molecular analysis of avian circadian clock genes. Brain Res Mol Brain Res 78:207-215.

Zeng H, Qian Z, Myers MP, Rosbash M (1996) A light-entrainment mechanism for the Drosophila circadian clock. Nature 380:129-135.

Zheng B, Larkin DW, Albrecht U, Sun ZS, Sage M, Eichele G, Lee CC, Bradley A (1999) The mPer2 gene encodes a functional component of the mammalian circadian clock. Nature 400:169-173.

Zhuang M, Wang Y, Steenhard BM, Besharse JC (2000) Differential regulation of two period genes in the Xenopus eye. Brain Res Mol Brain Res $82: 52-64$.

Zylka MJ, Shearman LP, Weaver DR, Reppert SM (1998) Three period homologs in mammals: differential light responses in the suprachiasmatic circadian clock and oscillating transcripts outside of brain. Neuron 20: 1103-1110. 